\title{
Kinerja Wirausahawati Umkm Diy Berbasis Orientasi Kewirausahaan Di Masa Pandemi Covid-19
}

\begin{abstract}
Sofiati
STIE Widya Wiwaha Yogyakarta

sofiatibg@gmail.com

Received: 08 Nopember 2020; Accepted: 23 Desember 2020; Published: 25 Desember, 2020

Abstrak

Perempuan semakin memiliki peran penting dalam meningkatkan perekonomian negara melalui sektor UMKM. Kondisi pandemi covid-19 bisa berdampak menurunnya kinerja wirausahawati UMKM atau sebaliknya justru ada peningkatan kinerja di beberapa UMKM sebagai akibat perilaku proaktif, inovatif wirausahawati dan keberanian mengambil risiko.Penelitian ini bertujuan untuk menganalisis faktor yang mempengaruhi kinerja wirausahawati berbasis orientasi kewirausahaan UMKM DIY di masa pandemi. Penelitian ini menggunakan desain kuantitatif kausal.Sumber data berdasarkan survey. Pengambilan sampel menggunakan teknik random sampling sebanyak 100 . Metode analisis data menggunakan analisis regresi berganda. Hasil penelitian menunjukkan bahwa secara simultan orientasi kewirausahaan yang terdiri dari faktor keproaktifan, keinovasian ,dan risk taking terbukti signifikan mempengaruhi kinerja wirausahawati UMKM DIY di masa pandemi Covid-19. Namun secara parsial faktor orientasi kewirausahaan (risk taking) tidak terbukti signifikan mempengaruhi kinerja wirausahawati UMKM DIY di masa pandemi Covid-19. Kesimpulan penelitian menunjukkan bahwa kinerja wirausahawati UMKM DIY selama pandemi Covid19 berbasis orientasi terbukti signifikan kecuali orientasi keberanian dalam mengambil risiko. Ketidaksignifikannya ini disebabkan perbedaan karakteristik jenis usaha sehingga tingkat risiko akan berbeda. Keberanian mengambil risiko pada wirausahawati UMKM juga berbeda.
\end{abstract}

Kata Kunci: proaktif, inovatif, risk taking,kinerja wirausahawati

\begin{abstract}
Women are increasingly having an important role in improving the country's economy through the umkm sector. The condition of the Covid-19 pandemic could have an impact on decreasing the performance of women workers or vice versa, in fact there wasan increase in oerformance in several umkm as a result of proactive, innovative behavior and courage in taking risks from entrepreneurs.this study aims to analyze the factors that influence the performance of self-employed entrepreneurs based on the entrepreneurship orientation of umkm diy.

This study uses a causal quantitative deisgn.data source based on survey.technique sampling using random sampling of 100.method of data analysis using multiple regression analysis.the results showed that simultaneously the entrepreneurial orientation of women entrepreneurs consisting of factors of proactiveness,
\end{abstract}


innovativeness, and risk taking to significantly affect the performance of umkmdiy entrepreneurs during the covid19 pandemic. However, partially risk taking entrepreneurial orentation factors are not proven to significantly affect the performance of umkm diy entrepreneurs during the covid 19 pandemic.the conclusion of the study shows that the performance of umkm female entrepreneurs during the pandemic covid19 based on entrepreneurrial orientation is proven to be significant except for the risk taking.this insignificance is due to different types of business so that the level of risk and risk taking preference will be different.

Key words: Entrepreneurs Performance; Innovative; Proactive; Risk Taking;

\section{PENDAHULUAN}

Tantangan dan peluang bagi perempuan dalam menjalankan usahanya di sektor UMKM banyak ditemui di negara Arab Saudi, demikian juga di negaranegara Timur Tengah lainnya dibandingkan di negara - negara barat (Javadian \& Singh dalam (Al-Kwifi et al., 2020) namun di Indonesia perempuan semakin memiliki peran penting dalam meningkatkan perekonomian negara melalui sektor Usaha Mikro, Kecil, dan Menengah (UMKM). Hal ini menunjukkan adanya partisipasi perempuan yang terlibat di sektor UMKM, total UMKM di tahun 2018 mencapai 57,83 juta, dari jumlah tersebut 37 juta atau 60 persen UMKM di Indonesia dikelola oleh perempuan (Bank indonesia, 2018). Apalagi di situasi pandemi covid-19 ini banyak yang bertransformasi ke UMKM.

Menurut Ahmed dikutip (Ali \& Ali, 2014) wirausahawati adalah perempuan yang bisa memainkan peran penting dalam pembangunan perekonomian terutama di sektor usaha kecil. Dalam pemberdayaan perempuan memilih kewirausahaan untuk menyeimbangkan tanggung jawab pekerjaan dan potensi penghasilan dengan komitmen keluarga. Faktor faktor yang mempengaruhi kesuksesan entrepreuner perempuan, kewirausahaan gender telah memperoleh minat yang signifikan karena dapat membantu pendidik dan pembuat kebijakan meningatkan partisipasi perempuan dalam proses kewirausahaan Malmstrom, Johansson, \& Wincen dikutip (Al-Kwifi et al., 2020);(AshimaBhatnagar et al., 2017); (Buttner \& Moore, 1997).

Di Indonesia pengalaman dari adanya krisis ekonomi tahun 1997 membuktikan bahwa UMKM mampu menyelamatkan pertumbuhan perekomian dimasa krisis. Banyak hal di lapangan menunjukkan bahwa wirausahawati UMKM 
pada kondisi pandemi Covid-19 berperan dalam pengembangan kewirausahaan. Namun dampak sosial dan ekonomi dari Covid-19 di Bangladesh dalam ambang batas yang belum pernah terjadi sebelumnya (Uddin, 2020). Permasalahannya adalah kondisi pandemi covid-19 apakah berdampak menurunnya kinerja berbasis orientasi kewirausahaan wirausahawati UMKM DIY atau sebaliknya justru ada peningkatan kinerja di beberapa UMKM sebagai akibat perilaku proaktif, inovatif wirausahawati dan keberanian mengambil risiko. Penelitian ini bertujuan untuk menganalisis faktor yang mempengaruhi kinerja wirausahawati berbasis orientasi kewirausahaan UMKM DIY di masa pandemi.Kebaruan penelitian ini dengan penelitian sebelumnya adalah dalam hal obyek, situasi dan variabel penelitian.

Penelitian pendahuluan orientasi kewirausahaan antara lain . Arshad (2014); (Hussain Haider, 2017); Zara dan Covin yang dikutip (Ali \& Ali, 2014) orientasi kewirausahaan merupakan sarana potensial untuk menyegarkan dan menstimulasi perusahaan yang sudah ada yaitu melalui keproaktivan, keinovasian, dan keberanian mengambil risiko. Adapun pendapat Arshad (2014) orientasi kewirausahaan sebagai salah satu faktor tercapainya keberhasilan usaha, sehingga hubungan antara orientasi kewirausahaan dengan kinerja perusahaan menjadi menarik untuk dijadikan sebuah penelitian. Peran perempuan yang memiliki orientasi kewirausahaan memberikan dampak pada keinovasian dan keberanian berisiko terhadap kinerja , namun tidak terbukti adanya dampak keproaktivan terhadap kinerja wirausahawati UMKM di Somalia (Ali \& Ali, 2014). Hasil temuan Al-Kwifi et al. (2020) menunjukkan bahwa dalam memulai suatu bisnis dipengaruhi oleh faktor motivasi mahasiswa perempuan untuk membangun bisnis mereka sendiri. Sedangkan (Jati,2009) dalam temuannya membuktikan bahwa motivasi kaum perempuan memang didorong oleh keinginan berprestasi sama dengan kaum laki - laki dan menunjukkan diri bisa mandiri sebagai wirausahawati. Kendala bagi perempuan yang berwira usaha adalah faktor personal, dimana faktor personal ini berkaitan dengan peran ganda perempuan mempengaruhi keberhasilan 
usaha. Prestasi, affiliasi, otonomi, dan dominasi menjadi faktor penjelas tingkat intensi kaum perempuan memilih karir sebagai wirausahawati di Kota Malang.

Hubungan orientasi kewirausahaan melalui konsep keproaktifan dan kinerja wirausahawati UMKM, pencapaian kinerja dipengaruhi faktor individu dan lingkungan organisasinya, panduan evaluasi kinerja menurut Neal Jr dikutip Anwar Prabu (2014) antara lain pemenuhan stnadar akurasi, prestasi dalam menyelesaikan tanggung jawab dan tugas; menunjukkan efektifitas administrasi; analisis secara efektif; berkomunikasi dengan pihak lain; menunjukkan kompetensi baik kemampuan maupun kulaitas; bekerja sama dengan orang laim; menunjukkan daya imaginasi dan kreativitas; pengambilan keputusan dan pemberian solusi; pendelegasian; dapat diandalkan; improvisasi, inisiatif; inovasi, keahlian interpersonal; motivasi; pengetahuan ; pembelajaran; dan negosiasi.Keberhasilan atau kegagalan usaha bagi entrepreunerial perlu adanya pengukuran (Osborne dan Ted Galben,1996), penghargaan terhadap kegagalan akan menciptakan dorongan untuk belajar mencapai keberhasilan. Dengan menidentifikasi keberhasilan usaha maka pengusaha dapat belajar dari kesuksesannya apakah dari inovasi produk atau jasa yang sering gagal. Drucker dalam Obsborne dan Ted Galben (1996) menyatakan ketika sebuah produk atau jasa dengan tak terduga ada beberapa pelajaran penting harus dipelajari.Menurut Yuyus Suryana dan Khatib Bayu (2014) tercapainya suatu keberhasilan tergantung dari visi,motivasi dan kompetensi setiap individu.apabila seseorang tidak tercapai suatu kesuksesan kemungkinan disebabkan visinya terlalu ntinggi, sedangkan kompetensinya rendah walaupun motivasiya cukup tinggi.

Persaingan pasar di saat pandemi covid-19 ini, wirausawati dituntut untuk memperhatikan dan memanfaatkan peluang masa mendatang Vankatraman dikutip (Ali \& Ali, 2014) proaktif adalah mencari peluang baru tidak terbatas pada operasi saat ini. Beberapa hasil penelitian menunjukkan bahwa keproaktifan mempunyai pengaruh positif terhadap kinerja Arshad (2014); (Hussain Haider, 2017); (Ali \& Ali, 2014); (Wardi et al., 2017); (Tawas \& Djodjobo, 2014);(Ranto, 2016); (Nurhartani et al., 
2018) . Berdasarkan penjelasan teori dan studi sebelumnya diatas maka hipotesis (H1) yang diajukan adalah keproaktifan berpengaruh positif dan signifikan terhadap kinerja wirausahawati UMKM DIY. Keinovatifan, keproaktifan, risk taking ,otonomi, dan agresivitas kompetitif merupakan indikator orientasi usaha (Rauch et al., 2009) adapun kinerja menurut Riyanti (2003) adalah adanya pertumbuhan penjualan, keunggulan bersaing,dan terpenuhinya kepuasan pelanggan .Inovasi menurut Jones (2004) merupakan proses pemanfaatan ketrampilan dan sumberdaya agar berkembang sehingga dapat menjawab kebutuhan. Wawuruntu (2016) inovasi dilakukan melalui berbagai pemikiran dan pembaharuan, gagasan baru, sistem dan metode baru, pendekatan lain, mengumpulkan informasi terbaru,memkai lat yang baru serta memperbaharui hal - hal lain. Hasil penelitian (Diah \& Pramayani, 2018) bahwa perilaku inovatif memiliki pengaruh positif terhadap produktivitas kerja di Bumbu Bali Restoran. Wawuruntu (2016) perusahaan mampu menerapkan perilaku yang inovatif bagi karyawan yang dapat meningkatkan produktivitas. Beberapa hasil penelitian menunjukkan bahwa keinovatifan mempunyai pengaruh positif terhadap kinerja (Arshad et al., 2014) ; (Hussain Haider, 2017); (Ali \& Ali, 2014); (Wardi et al., 2017); (Tawas \& Djodjobo, 2014);(Ranto, 2016);(Nurhartani et al., 2018) . Berdasarkan penjelasan teori dan studi sebelumnya diatas maka hipotesis (H2) yang diajukan adalah keinovatifan berpengaruh positif dan signifikan terhadap kinerja wirausahawati UMKM DIY. Risk taking mengacu Lumpkin dan Dess (2001) bahwa pengambilan risiko adalah kemampuan aktif entitas bisnis untuk mengejar peluang walaupun peluang tersebut mengandung risiko dan hasilnya belum pasti. Menurut Suryana (2008) wirausahawan yang berani menanggung risiko adalah orang yang selalu ingin menjadi pemenang dan memenangkan dengan cara yang baik. Keberanian menanggung risiko tergantung pada daya tarik stiap alternatif, siap mengalami kerugian, dan kemungkinan relatif untuk sukses atau gagal. Pemilihan untuk pengambilan risiko ditentukan oleh keyakinan diri, kesediaan untuk menggunakan kemampuan, kemampuan untuk menilai risiko. Beberapa hasil penelitian menunjukkan bahwa keinovatifan mempunyai pengaruh positif 
terhadap kinerja antara lain (Ali \& Ali, 2014); (Wardi et al., 2017); (Tawas \& Djodjobo, 2014);(Ranto, 2016); (Nurhartani et al., 2018). Berdasarkan teori dan penelitian sebelumnya maka hipotesis (H3) yang diajukan adalah risk taking berpengaruh positif dan signifikan terhadap kinerja wirausahawati UMKM DIY

\section{METODE}

Penelitian ini menggunakan desain kuantitatif kausal. Sumber data diperoleh berdasarkan survei. Data yang diperoleh menggunakan teknik wawancara dan penyebaran kuesioner Sampel diambil secara random sebanyak 100 wirausahawati UMKM di DIY dengan berbagai jenis usaha. Adapun pengukuran dimensi variabel menggunakan skala Likert lima poin. Pre -test dilakukan dengan menyebar kuesioner kepada 30 responden dengan tujuan untuk meyakinkan validitas dan reliabilitasnya. Pengukuran variabel orientasi kewirausahaan perempuan melalui tiga dimensi antara lain: keproaktifan : berani bereksplorasi dan bereksperimen agar meraih peluang. Keinovatifan menggunakan 4 pertanyaan antara lain melihat peluang, mengeluarkan ide, memperjuangkan, dan aplikasi. Risk taking mengacu (Rauch et al., 2009) mempunyai keberanian dalam pengambilan risiko, mempunyai keberanian dalam mengambil keputusan dengan probabilitas risiko, Sedangkan variabel kinerja melalui 3 indikator pertumbuhan penjualan, rasio laba terhadap penjualan, pengembangan produk baru mengacu Anwar Prabu (2014). Metode analisis data menggunakan analisis regresi berganda untuk mengetahui pengaruh variabel independen dengan variabel dependen, dengan menggunakan taraf signifikansi 5\%.

Untuk memastikan validitas variabel penelitian, validitas konsistensi internal harus diuji tingkat keandalannya terhadap item- item pertanyaan dalam kuesioner (Al- Kwifi et al, 2020) .Uji validitas ini dilakukan dengan cara membandingkan angka $r$ hitung dan $r$ tabel. Jika $r$ hitung lebih besar dari $r$ tabel dengan ketentuan minimal sebesar 0,30 maka indikator item pertanyaan dikatakan valid atau sebaliknya (Sugiono, 2013), Untuk menghitung r hitung matrik korelasi dengan bantuan progam SPSS versi 22 .Dari 16 item pertanyaan yang nilai 
korelasinya kurang dari 0,30 sebanyak 4 item antra lain pertanyaan item 3, item 6, item 9, dan item 14. Keempat item pertanyaan ini di keluarkan mengingat nilai signifikansi kurang dari 0,30 dengan demikian untuk analisis selanjutnya menggunakan 12 item pertanyaan. Uji reliabilitas dilakukan untuk mengetahui konsistensi internal dari ukuran yang digunakan mengacu Ghozali (2016) nilai Cronbach Alpha lebih dari 0,6 konsisten secara internal dan skala dianggap dapat diandalkan untuk analisis lebih lanjut. Pre test terhadap 30 responden dengan hasil uji reliabilitas nilai Cronbach Alpha 0,875.

\section{HASIL PENELITIAN DAN PEMBAHASAN}

Hasil penelitian menunjukkan bahwa terdapat tiga karakeristik responden berdasarkan jenis usaha. Karakteristik usaha, jumlah wirausahawati UMKM di musim pandemi covid-19 ini terbanyak adalah usaha Boga yaitu $41 \%$ yang terdiri dari Catering, Restorant,Cafe, dan Warung Makan kaki lima, kemudian di ikuti urutan kedua yaitu usaha Jasa sebanyak 30\% yang terdiri dari Modiste, Laundry, Rias Pengantin dan Salon; adapun urutan ke tiga adalah usaha Handy Craft sebanyak 22\% yang terdiri dari Kerajinan Perak, Batik, Cindera Mata , Keramik, dan Floris Plastik; dan urutan terakhir paling sedikit yaitu usaha Tanaman Hias sebanyak 7\% yang terdiri dari usaha khusus Tanaman Anggrek dan Aneka Tanaman Hias. Berdasarkan karakteristik demografi dan usia usaha,antara uumur 31- 45 tahun menduduki jumlah responden terbanyak yaitu sebesar 39\%, disusul usia kamum muda antara 20- 30 tahun sebanyak 32\%, dan terakhir usia diatas 46 tahun merupakan jumlah wirausahawati UMKM yang paling sedikit yaitu sebanyak 29\%.wirausawati dengan status tidak menikah jumlanya lebih banyak dibandingkan dengan yang sudah menikah. Tingkat pendidikan terbanyak diatas SMA yaitu sekitar $45 \%$ dan terendah wirausahawati berpendidikan SD-SMP sebanyak 20\%. Adapun usia usaha paling dominan pada usaha yang beroperasi antara 3-6 tahun yaitu sebanyak 40\%, terpendek 11\% pada usia usaha kurang dari satu tahun. 


\section{Pengujian Hipotesis dan Analisis}

Untuk menguji tiga hipotesis yang diajukan digunakan metode regresi berganda. Analisis regresi berganda digunakan untuk menguji pengaruh antara orientasi kewirausahaan perempuan dengan dimensi keproaktifan, keinovatifan, dan keberanian berisiko (risk taking) terhadap kinerja wirausahawati. Berikut ditunjukkan dalam tabel.1. ringkasan hasil uji regresi berganda dengan bantuan SPSS versi 22:

Tabel:1

Ringkasan Hasil Uji Regresi Berganda

\begin{tabular}{lllc}
\hline Variabel & Koefisien Regresi & $\mathrm{t}_{\text {hitung }}$ & Sign \\
\hline Konstanta & 2,432 & & \\
Proaktif & 0,432 & 4,882 & 0,000 \\
Inovatif & 0,007 & 2,493 & 0,014 \\
Risk taking & 0,032 & 0,481 & 0,632 \\
\hline $\mathrm{F}_{\text {hitung }}$ & $=10,530$ & & 0,000 \\
$\mathrm{R}$ & $=0,498$ & & \\
$\mathrm{R}$ Square & $=0,248$ & &
\end{tabular}

Sumber: data diolah,2020

Hasil pengujian regresi berganda dioeroleh nilai $\mathrm{R}$ sebesar 0.498 menunjukkan bahwa korelasi/hubungan antara keinofativan, keproaktifan, dan risk taking adalah kuat. Koefisien determinasi (R Square) sebesar 0.248 hal ini mmenunjukkan bahwa $24,8 \%$ variasi dari suatu pencapaian kinerja bisa dijelaskan oleh variabel proaktif, inovatif dan risk taking. Sedangkan sisanya 75,2\% kinerja dijelaskan oleh faktor lain misal tingkat otonomi maupun keagresifan wirausahawati UMKM di masa pandemi Covid-19.

Hasil analisis regresi berganda menunjukkan nilai koefisien regresi keproaktifan sebesar positif sebesar 0,432 berpengaruh secara signifikan terhadap kinerja wirausahawati UMKM DIY. Hal tersebut menunjukkan bahwa semakin meningkatnya perilaku proaktif wirausahawati kepada pelanggan maupun calon pelanggan dalam menghadapi persaingan pasar maka kinerja akan meningkat sebesar 0,432. Hasil positif sebesar 0,007 dan signifikan menunjukkan bahwa perilaku inovatif mempunyai pengaruh signifikan terhadap kinerja. Hal ini bermakna bahwa semakin meningkatnya berinovasi dalam usaha ini maka kinerja 
akan meningkat 0,007 . Variabel Orientasi kewirausahaan melalui dimensi risk taking nilai koefisien regresi sebesar 0,032 mempunyai makna bahwa setiap peningkatan risk taking sebesar 0,032 maka semakin meningkat kinerja sebesar 0,302 walaupun tidak signifikan . Ketidaksignifikan tersebut bukan berarti risk taking tidak berpengaruh terhadap kinerja wirausahawati UMKM DIY. Bila dibandingkan dengan keinovasian yang terbukti signifikan mempengaruhi kinerja wirausahawati UMKM DIY maka pengaruhnya justru lebih kuat risk taking. Hal tersebut kemungkinan disebabkan tingkat risiko untuk setiap jenis usaha yang berbeda, disamping preferensi masing- masing respoden terhadap risiko juga berbeda. Mengingat tingkat keagresifan dan otonomi wirausahawati yang berbeda. Dari ketiga variabel independen tersebut faktor yang paling dominan berpengaruh terhadap kinerja adalah keproaktifan megingat nilai koefisien regresi paling besar yaitu 0,432 .

Adapun hasil uji ANOVA atau F test pada regresi berfungsi sebagai uji simultan untuk menentukan apakah secara serentak orientasi kewirausahaan dengan dimensi keproaktifan, keinovatifan, dan risk taking berpengaruh terhadap kinerja wirausahawati UMKM DIY Berdasarkan pengujian hipotesis menunjukkan nilai F hitung sebesar 10,530 dengan tingkat signifikansi 0,000 . Nilai probabilitas 0,000 jauh lebih kecil dari 0,05 hal tersebut bermakna bahwa model regresi berganda yang diajukan dalam penelitian ini bisa digunakan untuk memprediksi kinerja wirausahawati UMKM DIY.

Pengujian secara parsial masing - masing dimensi terhadap kinerja melalui Uji t. Pengujian dilakukan untuk menguji signifikansi dimensi variabel keproaktifan, perilaku keinovatifan dan keberanian berisiko (risk taking) secara parsial terhadap kinerja. Hasil uji menunjukkan bahwa angka signifikansi variabel keproaktifan sebesar 0,000 lebih kecil dari taraf signifikansi yang disyaratkan $5 \%$ atau 0,05 maka hipotesis (H1) yang diajukan bahwa keproaktifan berpengaruh secara positif signifikan terhadap kinerja terbukti dan diterima. Hasil temuan ini sejalan dengan temuan (Ali \& Ali, 2014); (Ranto, 2016); Wulandary et al.(2017); 
(Tawas \& Djodjobo, 2014);(Wardi et al., 2017) namun temuan ini tidak sejalan dengan (Susanto, 2012).

Hipotesis (H2) yang diajukan bahwa keinovatifan berpengaruh secara positif signifikan terhadap kinerja terbukti dan diterima mengingat nilai signifikansinya sebesar 0,014 lebih kecil dari 0,05. Hasil temuan ini sejalan dengan temuan Ali dan Abdel (2014); (Wulandary, 2018); (Tawas \& Djodjobo, 2014)Djodjobo dan Hendra (2014); tidak sejalan dengan temuan (Susanto, 2012). Hipotesis (H3) bahwa risk taking berpengaruh positif dan signifikan terhadap kinerja tidak terbukti dan hipotesa (H3) ditolak mengingat nilai signifikansinya 0,632 lebih besar dari taraf yang signifikansi yang disyaratkan sebesar 0,05. Temuan ini tidak sejalan dengan (Ali \& Ali, 2014);(Susanto, 2012); (Nurhartani et al., 2018); (Ranto, 2016). Namun hasil penelitian ini mendukung Lumpkin dan Dess yang dikutip (Akehurst et al., 2012) bahwa perusahaan atau UKM yang berorientasi kewirausahaan cenderung berperilaku proaktif, inovatif, dan risk taking tidak berlaku pada temuan ini mengingat jenis usaha dalam sampel ini berbeda beda sehingga tingkat risk taking yang diambil juga seharusnya berbeda. Hasil penelitian ini dikuatkan oleh model yang dibangun Wawuruntu (2016) bahwa pengambilan risiko dalam bekerja tidak selalu menjadi dorongan prestasi tetapi justru merugikan perusahaan apabila risiko tidak diperhitungkan dengan baik ,disamping itu bisa melemahkan dorongan berprestasi dan semakin tidak memenuhi standar keberhasilan. Semakin besar dorongan untuk berprestasi maka cenderung tidak berani mengambil risiko.

\section{KESIMPULAN}

Berdasarkan analisis faktor faktor yang mempengaruhi kinerja wirausahawati, hasil penelitian menunjukkan bahwa kinerja berbasis orientasi kewirausahaan (proaktif dan inovatif) wirausahawati UMKM DIY selama pandemi Covid19 terbukti signifikan kecuali orientasi keberanian dalam mengambil risiko. Ketidaksignifikannya ini disebabkan perbedaan karakteristik jenis usaha sehingga tingkat risiko akan berbeda . Keberanian mengambil risiko pada wirausahawati UMKM juga berbeda, masing masing karakteristik jenis usaha yang berbeda beda antara usaha Boga, Jasa, Handy Craft, 
dan Tanaman Hias. Dari sisi perilaku keberanian berisiko wirausahawati di UMKM ini dipengaruhi juga oleh tingkat preferensi masing masing wirausahawati tersebut di situasi pandemi Covid-19 ini.

\section{DAFTAR RUJUKAN}

Akehurst, G., Simarro, E., \& Mas-Tur, A. (2012). Women entrepreneurship in small service firms: motivations, barriers and performance. The Service Industries Journal, 32(15), 2489-2505. https://doi.org/10.1080/02642069.2012.677834

Ali, A. Y. S., \& Ali, A. H. (2014). Entrepreneurial orientation and performance of women owned and managed micro and small enterprises in Somalia. ZENITH International Journal of Multidisciplinary Research, 4(1), 25-36.

Al-Kwifi, O. S., Tien Khoa, T., Ongsakul, V., \& Ahmed, Z. U. (2020). Determinants of female entrepreneurship success across Saudi Arabia. Journal of Transnational Management, 25(1), 3-29. https://doi.org/10.1080/15475778.2019.1682769

Arshad, A. S., Rasli, A., Arshad, A. A., \& Zain, Z. M. (2014). The Impact of Entrepreneurial Orientation on Business Performance: A Study of Technology-based SMEs in Malaysia. Procedia - Social and Behavioral Sciences, 130(1996), 46-53. https://doi.org/10.1016/j.sbspro.2014.04.006

AshimaBhatnagar, Bhardwaj, B. R., \& Mittal, V. (2017). Women Entrepreneurship : A Tool for Work Life Balance. International Conference on Technology and Business Management, 44-50.

BI 2018.www.bi.go.id.umkm. (2018).

Buttner, E. H., \& Moore, D. P. (1997). Women's organizational exodus to entrepreneurship: Self-reported motivations and correlates with success. Journal of Small Business Management, 35(1), 34-46.

Diah, A. A. S., \& Pramayani, I. (2018). 57-Article Text-113-1-10-20180731. 2, 1-15.

Hussain Haider, S. (2017). Entrepreneurial Orientation and Business Performance of Manufacturing Sector Small and Medium Scale Enterprises of Punjab Pakistan. $\begin{array}{lllll}\text { European Business } \quad \text { \& } & \text { Management, }\end{array}$ https://doi.org/10.11648/j.ebm.20170302.12

Nurhartani, Y., Rosmiati, E., \& Sova, M. (2018). Pengaruh Orientasi Pasar Dan Orientasi Kewirausahaan Terhadap Peningkatan Kinerja Usaha Mikro Kecil Menengah ( UMKM ) pada Industri Makanan Di Kecamatan Cipayung Jakarta Timur. Jurnal Administrasi Dan Manajemen, 9(1), 90-103. 
Ranto, D. W. P. (2016). Pengaruh orientasi Kewirausahaan terhadap kinerja UMKM bidang kuliner di Yogyakarta. Jurnal Bisnis, Manajemen, Dan Akuntansi, III(2), 111 .

Rauch, A., Wiklund, J., Lumpkin, G. T., \& Frese, M. (2009). Entrepreneurial orientation and business performance: An assessment of past research and suggestions for the future. Entrepreneurship: Theory and Practice, 33(3), 761-787. https://doi.org/10.1111/j.1540-6520.2009.00308.x

Susanto, P. (2012). Pengaruh Orientasi Pasar Pada Kinerja Perusahaan Kecil. Kajian Manajemen Bisnis, 1(September), 45-60.

Tawas, H., \& Djodjobo, C. (2014). Pengaruh Orientasi Kewirausahaan, Inovasi Produk, Dan Keunggulan Bersaing Terhadap Kinerja Pemasaran Usaha Nasi Kuning Di Kota Manado. Jurnal Riset Ekonomi, Manajemen, Bisnis Dan Akuntansi, 2(3), 1214-1224. https://doi.org/10.35794/emba.v2i3.5800

Uddin, M. (2020). Coronavirus : A Social Science Explanation; Measuring the Social and Economic Impact of Lockdown in Bangladesh. VII(Vii), 27-32.

Wardi, Y., Susanto, P., \& Abdullah, N. L. (2017). Orientasi Kewirausahaan pada Kinerja Usaha Kecil dan Menengah (UKM) Sumatera Barat: Analisis Peran Moderasi dari Intensitas Persaingan, Turbulensi Pasar dan Teknologi. Jurnal Manajemen Teknologi, 16(1), 46-61. https://doi.org/10.12695/jmt.2017.16.1.4

Wulandary, A. (2018). Pengaruh Orientasi Kewirausahaan Terhadap Kinerja Usaha Pada Industri UMKM Abon Ikan Di Kota Makassar The Effect of Entrepreneurship Orientation toward Business Performance In Fish Abon SME Industry In Makassar City. Journal of Food System \& Agribusiness, 1(2), 71-77. https://doi.org/10.25181/jofsa.v1i2.768 